\begin{tabular}{|c|c|}
\hline $\begin{array}{c}\text { European Association for the } \\
\text { and Power Quality (EA4EPQ) }\end{array}$ & $\begin{array}{c}\text { International Conference on Renewable Energies and Power Quality } \\
\text { (ICREPQ'12) } \\
\text { Santiago de Compostela (Spain), 28th to 30th March, 2012 }\end{array}$ \\
\hline
\end{tabular}

\title{
Solar Energy Laboratory: Summary of Ten Years Continuous Experiences
}

\author{
D. Dimitrov, V. Stoilkov and A. Iliev \\ Faculty of Electrical Engineering and Information Technologies \\ Sts Cyril and Methodius University in Skopje \\ 1000 Skopje (Macedonia) \\ Phone number: +38923062 224, Fax number: +38923064262 \\ e-mails: ddimitar@feit.ukim.edu.mk, stoilkov@feit.ukim.edu.mk, ailiev@feit.ukim.edu.mk
}

\begin{abstract}
As a result of nearly 30 years of research activities in the field, and a need for experimental work, in 2002 at the Faculty of Electrical Engineering and IT at "Sts Cyril and Methodius" University in Skopje, a Solar Energy Laboratory had been established. It mainly deals with stand-alone (incl. hybrid) photovoltaic systems, but the results of many experiments can be found useful in grid-connected system applications. In the paper several research and educational possibilities of the installed equipment are presented. For that purpose, the results of some experiments and equipment testing have been shown. Ideas for further improvements are also presented.

There are elaborated continuous (since 2002) onsite measurement values of the solar radiation and the ambient temperature. There is also presented a method for measuring the I-V characteristic of a photovoltaic generator, together with the approach for obtaining the values of its working parameters.
\end{abstract}

\section{Key words}

solar energy, photovoltaic systems, hybrid systems, laboratory, solar radiation database

\section{Introduction}

For decades, in many fields of the technical sciences, the Faculty of Electrical engineering and Information Technologies at "Sts Cyril and Methodius" University (UKIM-FEIT) in Skopje, is one of the leading institutions in the Republic of Macedonia and wider. One of those fields is the solar energy application. Research, education and know-how transfer activities in this field have been performing about four decades [1]. However, as an electrical engineering faculty, it mainly deals with photovoltaic systems.

Within the years, the lack of experimental work was evident and it was pointed as an obstacle for further development of applicative and educational activities. Facing with this situation, the Faculty had started activities for establishing a Solar Energy Laboratory [1]. In 2002, these efforts resulted with building of the Laboratory, which was equipped according to the obtained financing and donations at that time. After, the Laboratory has been continually upgraded. Up today (2012), the laboratory has 10 years of work and experience. Within this period, many activities have been performed.

In this paper, the installed equipment in the laboratory is briefly described. The measurements of I-V characteristics of PV modules are presented, as well as the identification of their relevant parameters. There are presented measurements of the global solar radiation, as well as other meteorological parameters. In the paper is also noted the positive experiences and problems that have appeared within the first 10 years of work.

The experiences and results from the measurements underline that the Laboratory is capable for serious education and research work. The paper shows that with enthusiasm, dedicated work and small financing, a strong basis for development of renewable energy sources, with a special stress on the photovoltaic systems.

\section{Equipment description}

From the beginning, the main part of the Solar Energy Laboratory at UKIM-FEIT is a photovoltaic (PV) system. It is consisted of $4 \mathrm{PV}$ modules (Total Energie TE-1200, monocrystalline cells, $120 \mathrm{Wp}$ ), power conditioning unit (inverter, charger and controller) (Compact Studer C2423, $2.3 \mathrm{kVA}$ ), 8 VRLA batteries (Sonnenshine A400, $12 \mathrm{~V}, 50 \mathrm{Ah}$ ) and other supplemental equipment, shown on Fig. 1. The system is highly flexible and can be easily reconfigured, according the educational, testing and research requirements. The modules can be arbitrary connected (in series or in parallel). They are placed on mounts which can provide manual tilting in one axe (Fig. 2 and Fig. 3).

The system is able to operate as hybrid. To the power conditioning unit there is a possibility to connect and to control the switching (on and off) of a diesel generator. Currently this device is lacking, and the public electrical grid plays the role of it, instead. 


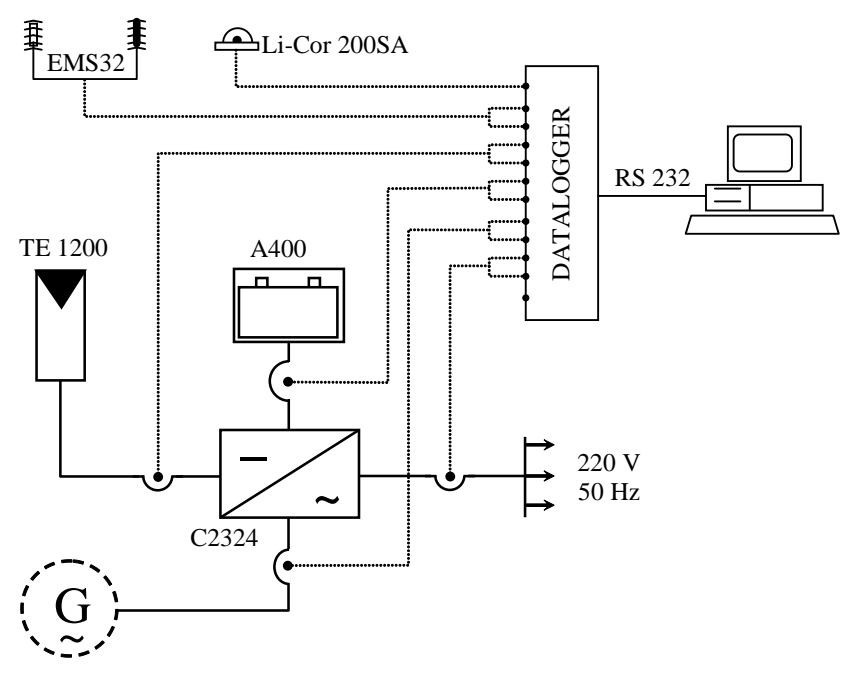

Fig. 1. Configuration of the PV system

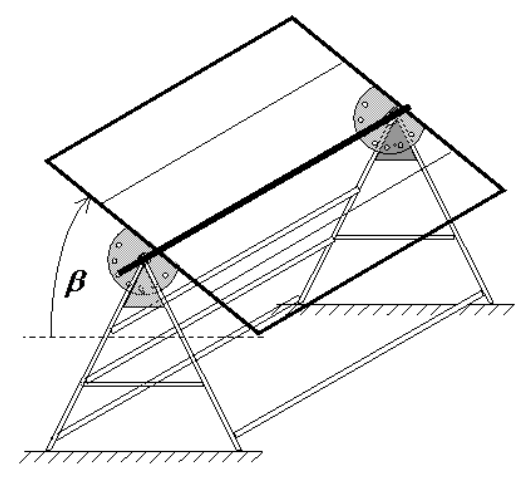

Fig. 2. Mounting structure for the modules

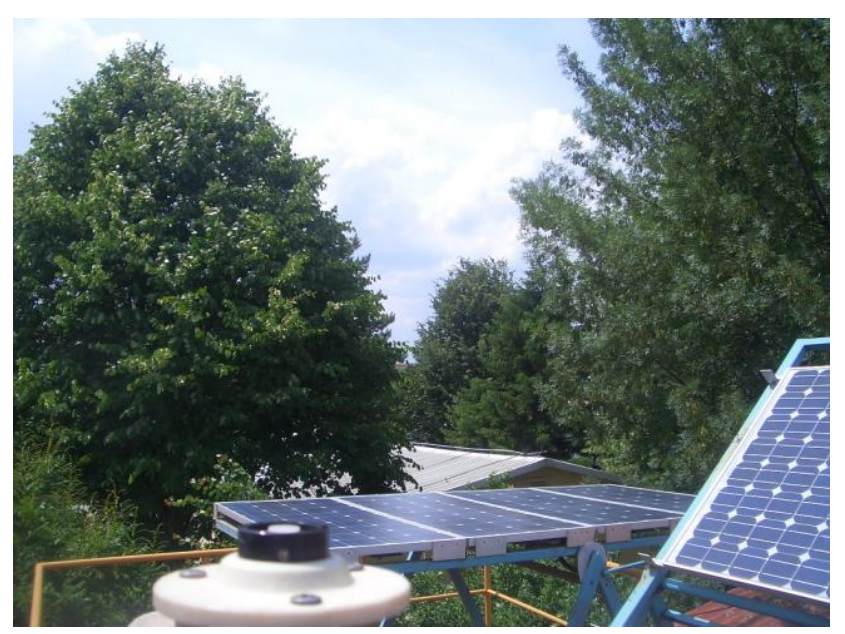

Fig. 3. PV modules and solar radiation measurement sensor

The Laboratory incorporates a considerable measuring system. It enables to measure electrical parameters (voltages, currents, power, etc.) in several points in the described PV system, but it also gives a possibility to measure the global solar radiation on a horizontal plane (with a pyranometer LiCor SA-200), air temperature and humidity (with a sensor EMS32), etc. The measurement signals are collected and stored to a datalogger (UNILOG
MiniCube VX-12, $12+1$ channel). It can store more than 220000 values. It is connected to mains supply, but for shorter time it can operate with the electricity stored in the rechargeable batteries. The recorded data to the datalogger, via RS232 interface, can be downloaded to a computer.

The datalogger measures data in regular intervals. It is generally preset to perform measurements in every 2 minutes, and to save the averaged values in every 10 minutes. According to the requirements for the specific measurement this can be temporarily changed.

In 2005 , the laboratory was additionally equipped with two monocrystalline PV modules of $150 \mathrm{Wp}$, inverter and a battery charger, given by the manufacturer ISOFOTON.

\section{Example measurement results}

Within this paper, two example ways of using the Laboratory, will be demonstrated. Firstly, data from the continuous solar radiation and ambient temperature measurements will be shown. Then, the measurements of a PV module and a PV generator I-V characteristics will be demonstrated, as well as the obtaining of values of the relevant parameters.

\section{A. Solar radiation and air temperature measurements}

Long-term solar radiation and other meteorological databases with on-situ measurements are always favorable for proper planning and designing of systems that use the solar energy. Solar radiation, air temperature and humidity are continuously recorded since the beginning of the Laboratory operation in 2002. For the most of the time, the datalogger is set to measure data in every 2 minutes, and store the averaged values for 10 minute intervals. The meteorological data recorded in the mentioned manner are generally good enough for indepth research work [2]. For system performance simulations, these values are easily converted into hourly values. Occasionally, when the laboratory equipment is used for educational and other research activities, the datalogger is set to perform measurements only in shorter intervals, and hence, such incidences do not degrade the database. The geographical location co-ordinates of the Laboratory are $42.004559^{\circ} \mathrm{N}, 21.406452^{\circ} \mathrm{E}$.

On Fig. 4 there are presented the measurements of the global solar radiation on a horizontal plane, air temperature and humidity at the start of operation the laboratory (September 2002). On Fig. 5, 6 and 7 are presented the average monthly values of the measured data for the daily global solar radiation on a horizontal plane, the air temperatures and relative air humidity for the period September 2002 - December 2010. In all charts, with a solid line, the grand average monthly values are given. 


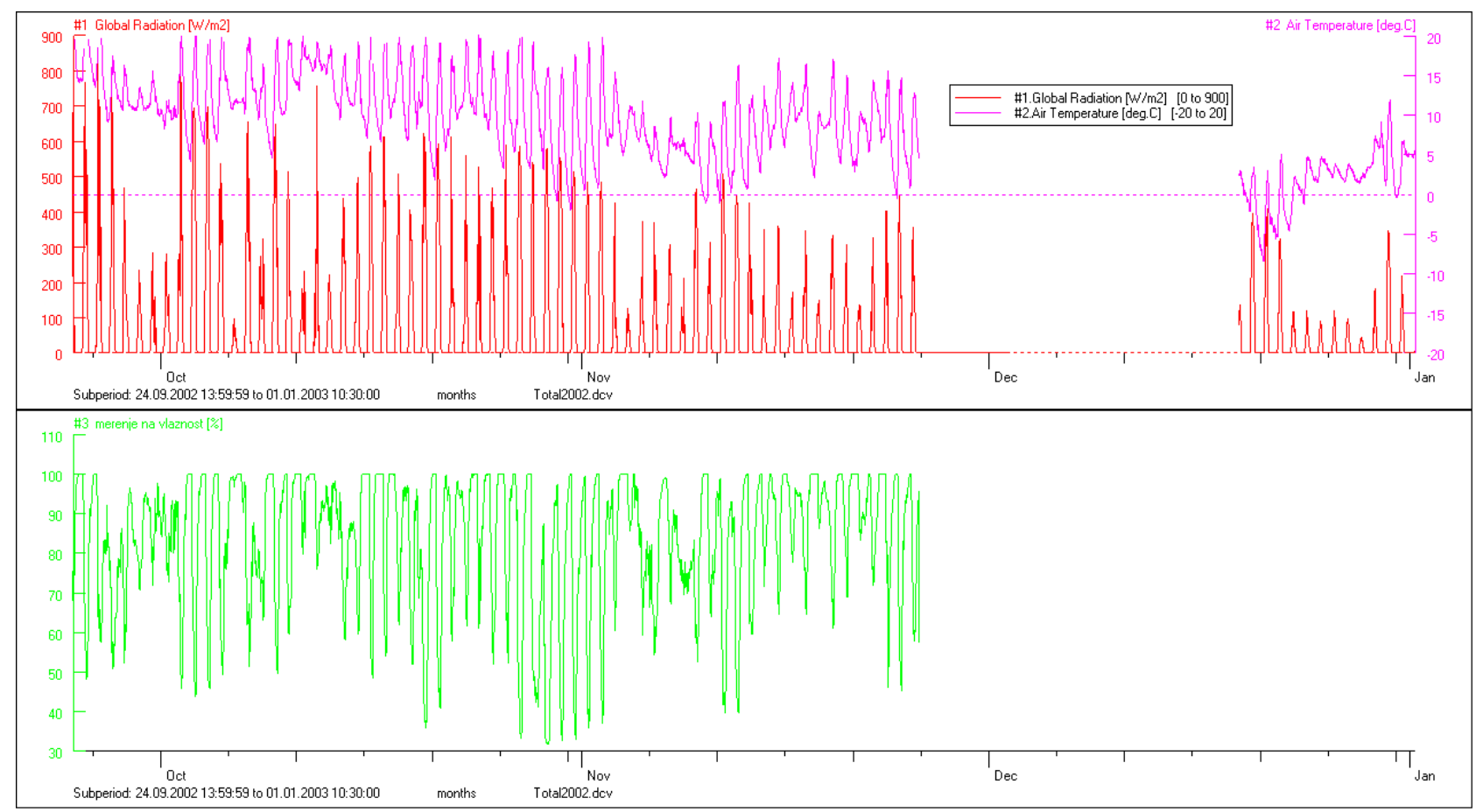

Fig. 4. Global solar radiation on a horizontal plane, air temperature and humidity measured in 2002

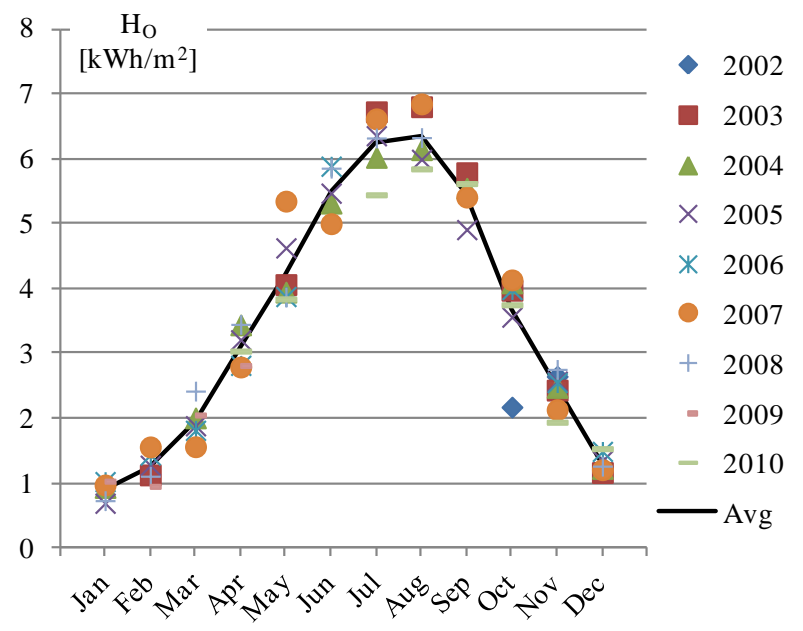

Fig. 5. Monthly averages of the daily values of the global solar radiation on a horizontal plane

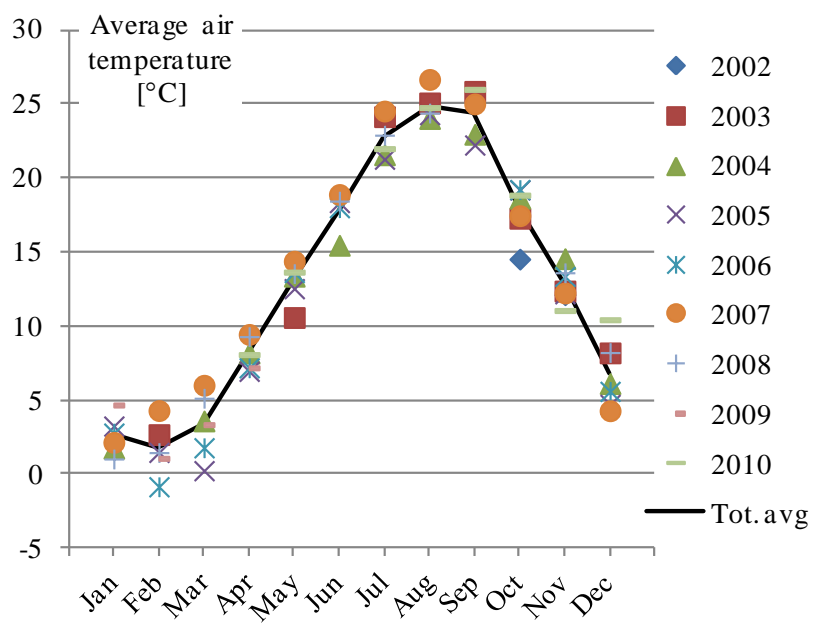

Fig. 6. Average monthly values of the air temperature

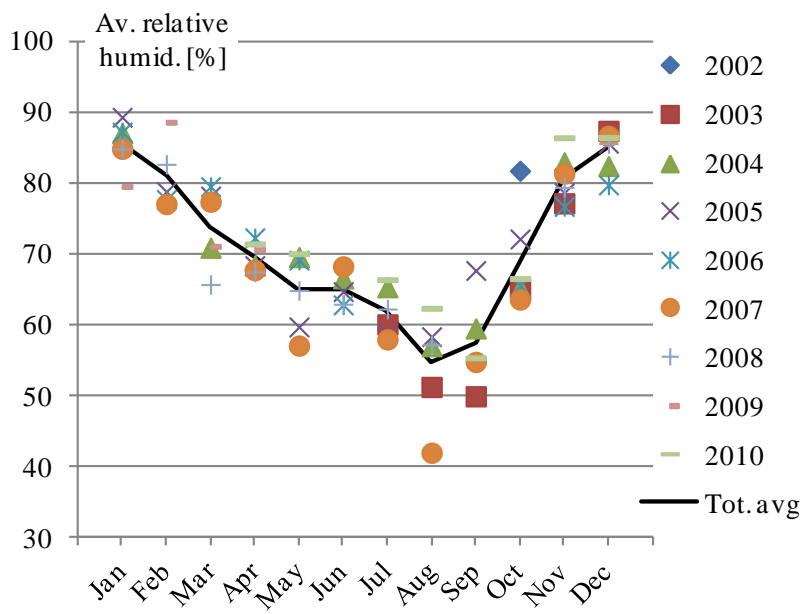

Fig. 7. Average monthly values of the air relative humidity

\section{B. I-V characteristics measurements}

The current-voltage (I-V) dependence is the most important characteristic that describes the operation of a PV devices. The I-V characteristic is a source for extraction of many relevant data such as: point with maximal power, open circuit voltage, shortcut circuit current, the quality or aging of the PV module or PV generator, as well as the operation of the PV system at whole. The most widely used theoretical model for the PV module I-V characteristic is the 4-parameter diode model [3], which is determined by an implicit analytical relation, given in (1).

$$
I=I_{\mathrm{L}}-I_{\mathrm{D}}=I_{\mathrm{L}}-I_{\mathrm{o}}\left[\mathrm{e}^{\frac{q}{\gamma k T_{\mathrm{c}}}\left(V+I R_{\mathrm{S}}\right)}-1\right]
$$

where: $I$ and $V$ are the PV module current and voltage, $I_{\mathrm{L}}$ is the light current, $I_{\mathrm{D}}$ is the diode current, $I_{\mathrm{o}}$ is inverse saturation current, $R_{\mathrm{s}}$ is the series voltage, $T_{\mathrm{c}}$ is the cell 
temperature, $q=1,602 \times 10^{-19} \mathrm{C}$ is the elementary electrical charge, $k=1,381 \times 10^{-23} \mathrm{~J} / \mathrm{K}$ is the Boltzmann constant, while $\gamma$ is the diode factor. The 4 parameters in the model are $I_{\mathrm{L}}, I_{0}, R_{\mathrm{s}}$, and $\gamma . R_{\mathrm{s}}$ and $\gamma$ are considered as constant, while the other two depend on the solar radiation $G$ and the PV cells temperature $T_{\mathrm{c}}: I_{\mathrm{L}}=I_{\mathrm{L}}\left(G, T_{\mathrm{c}}\right)$ and $I_{\mathrm{o}}=I_{\mathrm{o}}\left(T_{\mathrm{c}}\right)$.

The model parameter values are obtained with methodology explained in [4] using the manufacturer's data or data obtained by testing. With the following expressions, it is calculated the cell temperatures $T_{\mathrm{c}}$ [5], as well as the light current $I_{\mathrm{L}}$ and saturation current $I_{\mathrm{o}}$.

$$
\begin{gathered}
T_{\mathrm{c}}=\frac{G}{1000}\left(19,6 \cdot \mathrm{e}^{-0,223 \cdot w_{\mathrm{s}}}+14,6\right)+T_{\mathrm{a}} \\
I_{\mathrm{L}}=\frac{G}{1000}\left[I_{\text {sc,ref }}+\mu_{\mathrm{I}_{\mathrm{sc}}}\left(T_{\mathrm{c}}-25\right)\right] \\
I_{\mathrm{o}}=D T_{\mathrm{c}}^{3} \mathrm{e}^{-\frac{1,12 N_{\mathrm{s}} q}{\gamma k T_{\mathrm{c}}}}
\end{gathered}
$$

where: $w_{\mathrm{s}}$ is the wind speed (whish in the lack of data is assumed to be $1 \mathrm{~m} / \mathrm{s}), T_{\mathrm{a}}$ is the ambient temperature, $I_{\mathrm{sc}, \text { ref }}$ is the shortcut current at reference conditions $\left(G=G_{\text {ref }}=1000 \mathrm{~W} / \mathrm{m}^{2}\right.$ and $\left.T_{\mathrm{c}}=T_{\mathrm{c}, \text { ref }}=25^{\circ} \mathrm{C}\right), \mu_{\mathrm{I}_{\mathrm{sc}}}$ is the temperature coefficient for changing the shortcut current, $D$ is a coefficient that is eliminated in further computations and $N_{\mathrm{s}}$ is the number of cells in a PV module.

PV generators are consisted of strings of PV modules connected in series, and parallel strings. I-V characteristics of PV generators have the same shape as the characteristics of the PV modules. The parameters of the model are modified according the number of the PV modules connected in series $N_{\mathrm{PV}, \mathrm{s}}$ that are composing the strings, and the number of parallel strings $N_{\mathrm{PV}, \mathrm{p}}$. Namely: $I_{\mathrm{L}, \mathrm{G}}=I_{\mathrm{L}} N_{\mathrm{PV}, \mathrm{s}}, \quad I_{\mathrm{o}, \mathrm{G}}=I_{\mathrm{o}} N_{\mathrm{PV}, \mathrm{s}}, \quad R_{\mathrm{s}, \mathrm{G}}=\left(N_{\mathrm{PV}, \mathrm{s}} / N_{\mathrm{PV}, \mathrm{p}}\right) R_{\mathrm{s}} \quad$ and $\gamma_{\mathrm{G}}=\gamma N_{\mathrm{PV}, \mathrm{s}}$, where the index $G$ denotes that the parameter relates to the values for a $\mathrm{PV}$ generator.

On Fig. 8, is given the configuration of the system for measuring the I-V characteristics. For practical reasons, for measuring different segments of the characteristics, there are used three resistors with possibility of manual resistance variation, differing by their maximal allowable currents and resistances. In order to obtain satisfactory results, constant values of the incoming solar radiation and the cell temperature, are ensured by performing all measurements (about 20 points of the characteristics) within few minutes. To achieve this, the datalogger measuring interval is set to 10 seconds, which is long enough time period to manually change (and switch) the load resistance. In order to avoid the reflective solar radiation component at the modules' surface, they are tilted to a horizontal position (Fig 3). After completing the measurements, the recorded data is downloaded on a computer and performed the required computations.

On Fig. 9, there are shown the measurement results of the I-V characteristic of a PV generator consisted of 2 strings by $2 \mathrm{PV}$ modules connected in series, at a horizontal solar radiation of $G_{\mathrm{h}}=770 \mathrm{~W} / \mathrm{m}^{2}$ and air temperature $T_{\mathrm{a}}=29^{\circ} \mathrm{C}$. According to (2), the cell temperature is estimated to $T_{\mathrm{c}}=49.5^{\circ} \mathrm{C}$. The theoretical model is shown with a solid line. The values of the series resistance and the diode quality factor, using the PV module's manufacturer data are $R_{\mathrm{s}}=0.0302 \Omega$ and $\gamma=118.53$. However, the measurements show slight disparity in regard to the theoretical model. After several trial-anderror attempts for better fitting the measured data, the above mentioned parameters are adapted to $R_{\mathrm{s} \text {,adp }}=0.376 \Omega$ and $\gamma_{\mathrm{adp}}=118.48$. It is also adapted decreasing of the light transmittance of the modules' front surface due to aging for $3 \%$. The I-V characteristic using the adapted input data is shown with a dotted line. In this regard the coefficient of determination of the measured data by this line is $R^{2}=0.9924$ (ideally $R^{2}=1$ ).

Further, the presented model with adapted input data was tested for four different values of the solar radiation and the air temperature (Fig. 10). They show a high degree of matching $\left(R^{2} \approx 1\right)$ which is an indication that the fitting was correctly done.

The changed (adapted) parameter values $R_{\mathrm{s} \text {,adp }}$ and $\gamma_{\mathrm{adp}}$ result in shifting of the maximal power point. The rated voltage and current at the maximal power point are $V_{\text {mp,ref }}=16.9 \mathrm{~V}$ и $I_{\text {mp,ref }}=7.1$ A. Due to many reasons (aging, contact weakening, mismatch, etc.), the measurements and processing of the I-V characteristic show that the maximal power point was shifted to: $V_{\text {mp,ref_adp }}=16.6 \mathrm{~V}$ and $I_{\text {mp,ref_adp }}=6.6 \mathrm{~A}$. This means that the rated PV module peak power of $120 \mathrm{Wp}$ $(16.9 \mathrm{Vx} 7.1 \mathrm{~A})$, is decreased to 16.6 V x 6.6 A = 109.56 Wp. Additionally, there must be

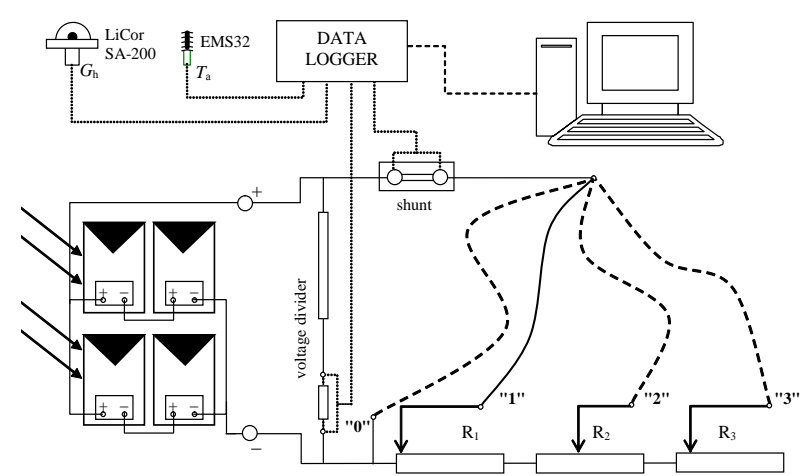

Fig. 8. Configuration for measuring the $\mathrm{I}-\mathrm{V}$ characteristic of PV module / generator

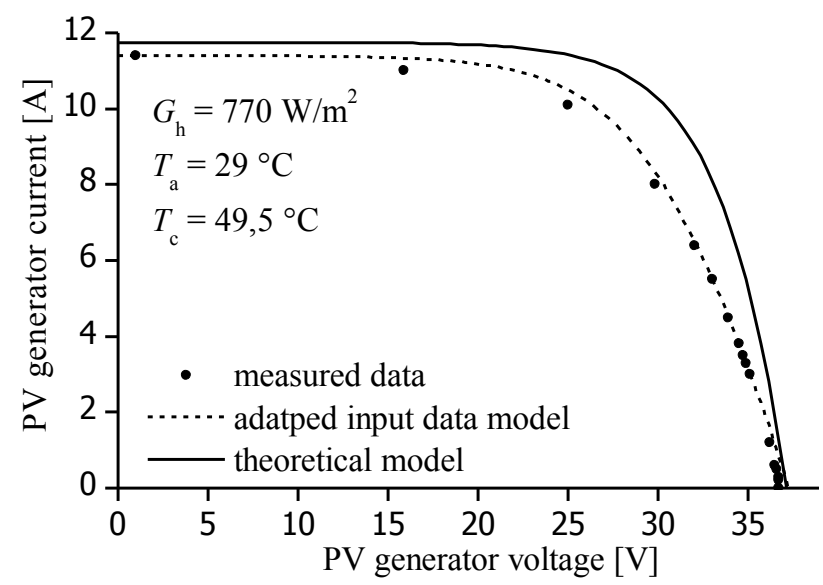

Fig. 9. Adapting of the I-V characteristic 


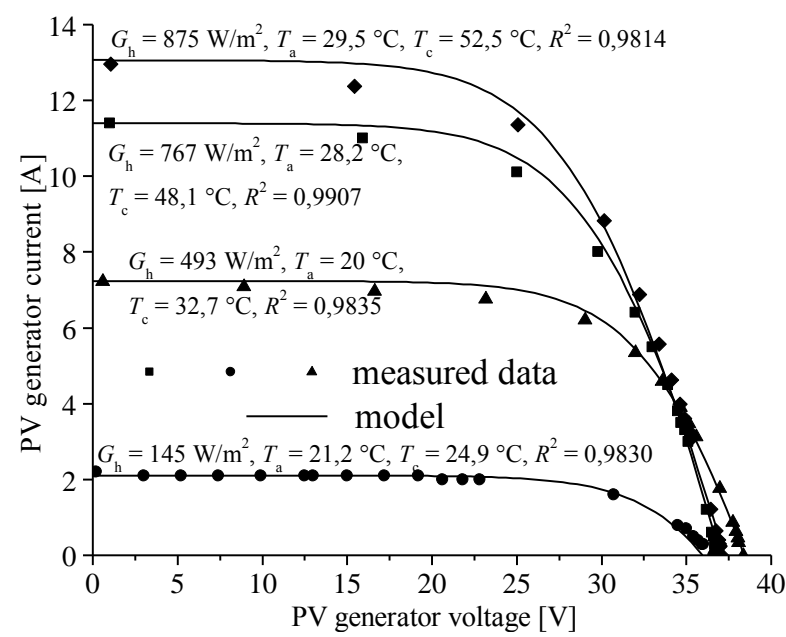

Fig. 10. I-V characteristics for different meteorological conditions

taken into account the degraded light transmittance of the modules' front surface for $3 \%$, the PV module's peak power is $106.27 \mathrm{Wp}$, which is reducing of $11.4 \%$ from the rated power.

\section{Experiences of operation and future plans}

The Laboratory has been continuously in use for about 10 years. The PV system has been used for laboratory exercises with the students of undergraduate, masters and $\mathrm{PhD}$ studies at UKIM-FEIT. During that time the equipment was properly operating. Due aging of the logger's battery and impossibility to recharge, from time to time the measurement system is switched off, which result with the gaps in the measured values databases.

Nevertheless, no major malfunction appeared on any device of the system. However, once the system was a subject of vandalism, when some of the wiring of the measuring system was damaged. The damage was not too serious, and it was fixed very soon. The system was out of operation for few days. The reason for the vandalism was not clear, but it is assumed that was a nasty game of young teenagers. However this is indication that PV systems could not be left on a self-operation and the security system must be unavoidable part of the systems.

In the future, enlarging the educational and research capabilities of the Laboratory is on the scope. Within this, equipping the Laboratory with a fully functional gridconnected PV system, acquiring of PV panels with different cell technology, as well as purchasing of more dataloggers are planned.

As a basis of the positive experiences of operation of the Solar Energy Laboratory, UKIM-FEIT started an ambitious project for establishing a multifunctional platform for education, research and promotion of several types of renewable energy sources (PVs, solar thermal, wind generators, biomass, etc). This will furthermore improve the capacities of the Faculty, as well as the development of the renewable energy source in the region.

\section{Conclusions}

The Solar energy laboratory at UKIM-FEIT exists as a support for university education, training, research, know-how transfer activities etc. in the field of solar energy, with a special focus on PV systems, for ten years.

In the paper, only few examples for using the Laboratory were presented. The possible ways of using the equipment are huge. The technical concept of the Laboratory is flexible and open for further upgrading.

The long term recorded database of the solar radiation and the air temperature is an essential starting point for simulation the behavior of systems for using the solar energy (thermal or PV).

At the Laboratory, there is a technical possibility to measure the I-V characteristics of any PV module, as well as an assembly of modules in a small PV generator. Estimating the relevant parameter values with the measurements in real conditions, will give a quantitative level of the PV module or PV generator quality and status, i.e. mismatch, aging effect.

The obtained knowledge and the lessons learnt from the Solar energy laboratory is a good basis for further improvements: enlarging the PV generator capacity, acquiring additional equipment for grid-connection, enlarging the system with a wind generator etc. It is a good basis for development research projects and applications in the field of use of the solar energy.

The Laboratory also enables students and staff from other universities, as well as the other experts, to do their education, research and PV equipment testing.

\section{Acknowledgement}

The main tribute for establishing the Solar Energy Laboratory at UKIM-FEIT had been done by Prof. Kiril I. Kocev.

\section{References}

[1] K. I. Kocev, D. Dimitrov, "Experimental photovoltaic system", in Proccedings of the International ZEMAK 4E Conference, Struga, 2002, Vol. 1, pp. 207-215;

[2] D. Kondrashov, Y. Shprits, M. Ghil, "Gap filling of solar wind data by singular spectrum analysis", Geophysical Research Letters, Vol. 37, Iss. 15, pp. 1-6, 2010.

[3] F. Lasnier, T. G. Ang, "Photovoltaic Engineering Handbook", IOP Publishing Ltd, New York, NY, 1990;

[4] J. F. Manwell, et al. "HYBRID2 - A Hybrid System Simulation Model - Theory Manual", Renewable Energy Research Laboratory, Department of Mechanical Engineering, Univ. of Massachusetts, 1998;

[5] D. L. King et al., "Field Experience with a New Performance Characterization Procedure, for Photovoltaic Arrays", $2^{\text {nd }}$ World Conf. and Exhibition on Photovoltaic Solar Energy Conversion, Vienna, Austria, 1998. 